\title{
Crónica de aspectos, aspersiones, cambios, arquetipos y estereotipos de la masculinidad
}

\author{
Carlos Monsiváis
}

Juego de epígrafes al amparo de las tradiciones

La versión de Él

Yo soy mexicano, mi tierra es bravía,

palabra de macho que no hay otra tierra

más linda y más brava que la tierra mía.

Yo soy mexicano, y a orgullo lo tengo

nací despreciando la vida y la muerte

y si echo bravata también la sostengo.

Mi orgullo es ser charro

valiente y bragado

traer mi sombrero con plata bordado

que nadie me diga que soy un rajado.

“El Mexicano”, canción de Manuel Esperón con letra de Ernesto Cortázar. Intérprete: Jorge Negrete.
La versión de Ella

La mujer que al amor no se asoma, no merece llamarse mujer, es cual flor que no esparce su aroma, como un leño que no sabe arder. La pasión tiene un mágico idioma que con besos se puede aprender, porque una mujer que no sabe querer no merece llamarse mujer.

Una mujer debe ser soñadora, coqueta y ardiente, debe darse al amor con frenético ardor para ser una mujer.

“Una mujer”, canción de Paul Mazurki. Intérprete: Elvira Ríos. 


\section{I}

\section{"Si no quiere que me lo madree, ni se le ocurra nacer en mi pueblo"}

E $n$ los años recientes, en cantidad abrumadora, libros, películas, programas de televisión, ensayos, informes y encuestas, abordan los temas de la masculinidad y la feminidad, en tanto prácticas cotidianas y en tanto conceptos de desarrollo histórico. Si las definiciones memorables de lo masculino y lo femenino han sido "árboles totémicos" de la conducta, hoy resultan comportamientos y teorías atravesados por los avances científicos y transformaciones de toda índole. En el caso de México, el análisis de la masculinidad pasa necesariamente por su vertiente más estentórea, el machismo, sucesiva y simultáneamente la obligación inevitable, el orgullo nacional, la exigencia de la vida en común, el espectáculo autoparódico, la pesadilla familiar, el peligro social, la sucesión de abismos del impulso; el espejo adonde acuden sólo capta positivamente la imagen ideal las generaciones anteriores.

¿Cómo describir muy sucintamente el machismo? A sabiendas de la enormidad de la empresa, consigno algunos de los rasgos:

- Proclama la autoridad de las conductas sustentadas en la tradición: "Nada puede tener de malo lo hecho por nuestros ancestros. Es parte del principio de identidad."

- Teatraliza y lleva al límite los prejuicios del patriarcado, en rigor su estrategia de continuidad. "Los prejuicios son nuestro título de propiedad anímica."

- Exhibe la debilidad comprobable de sus víctimas, y el peso de las instituciones que lo apoyan (la tradición, la ignorancia comparativamente mayor de las mujeres, la manipulación eclesiástica de los temores, las esperanzas y los sentimientos de culpa).

- Encabeza el linchamiento social, apenas disminuido en los tiempos recientes, de los alejados del estereotipo de lo "viril", los "afeminados".

- Es la traducción violenta y (siempre) melodramática del ideario de la supremacía masculina.

- Es la reelaboración de costumbres feudales y parafeudales fundamentadas en una ideología de cartón y piedra.

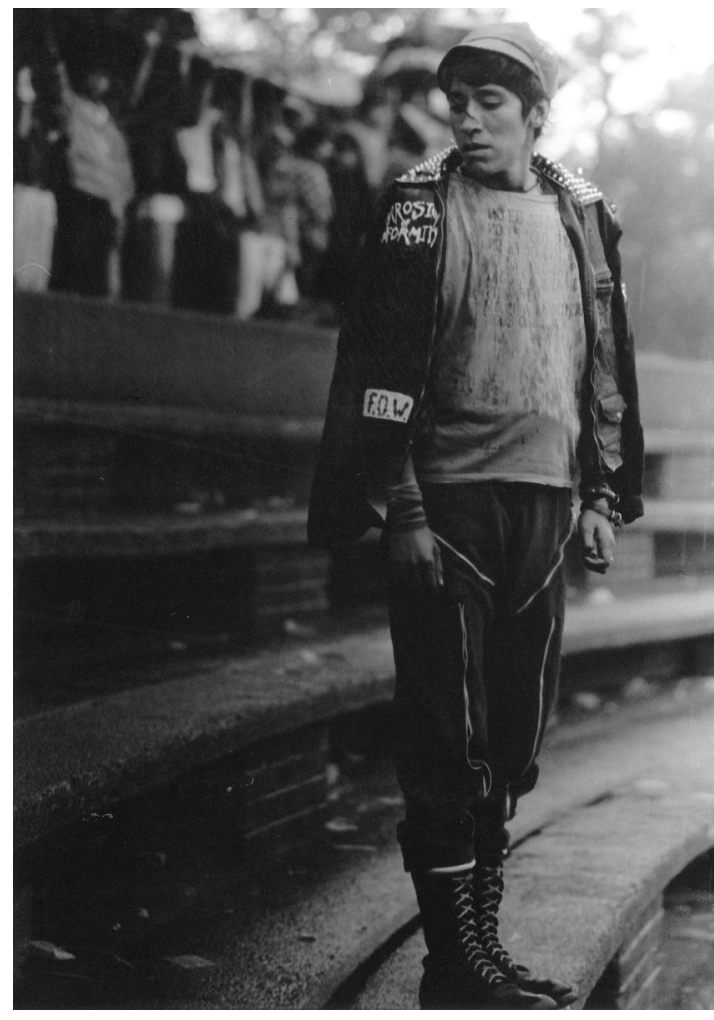

Foto: Arturo Fuentes.

\section{"No me levantes la voz, pinche vieja, que no vengo de humor para golpearte"}

Limitación constitutiva de toda sociedad, y entre cosas, el machismo en México se responsabiliza, entre otras tareas, de las siguientes:

- Retarda la modernización crítica y la (mínima) armonización social al sujetar durante un tiempo más que considerable a un poco más de la mitad de la población a la "minoría de edad" psíquica y al aplazar hasta el límite un trato laboral más equitativo, así como los procesos de conocimiento y autonomía de las mujeres (si la feminización de la economía es ya un proceso largo, la feminización de la vida académica es sólo un hecho irreversible a partir de la década de 1970).

- Convence a grandes sectores femeninos, en buena medida hasta el día de hoy, de su adscripción irremediable 


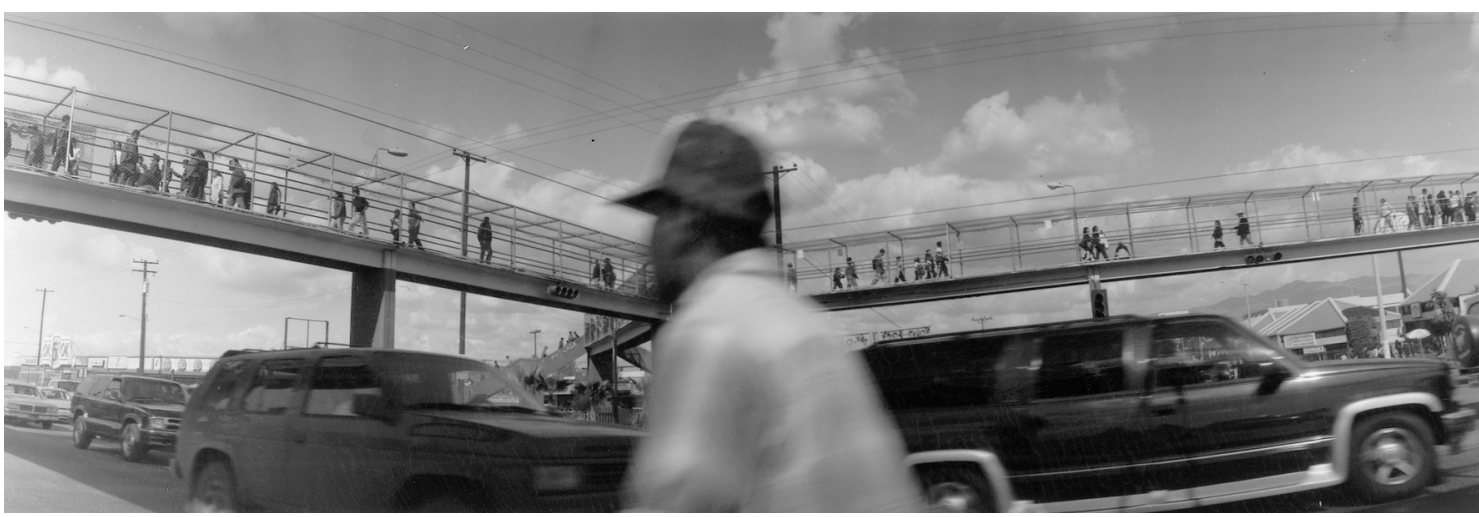

Foto: Arturo Fuentes.

al hogar, en un nivel, con frecuencia, al punto del aprisionamiento. Si la mujer es sólo ama de casa, la mujer nunca será el ama de su casa, aceptando más bien representar a Dios en la cocina.

- Eleva las tradiciones de la inferiorización femenina al rango de esencias de la Nación, alojando el sometimiento en "los altares" de la Mexicanidad. Si, en la mitología del tradicionalismo, México (la entidad monolítica de la leyenda, que le imprime a sus habitantes una psicología unívoca) quiere honrar su destino, fijará la clave de su dicha en el ser siempre igual, "fiel a tu espejo diario", y disculpará la violencia patriarcal hasta el fin. Por lo mismo, la "esencia" declarada de México es, de manera substancial, la limitación cruenta. Un país equitativo será aquel en donde dé igual si los ancestros —allí en donde radiquen - no se llamen a traición, y acepten, por intermedio de sus descendientes, el agravio de las transformaciones.

\section{II}

\section{Lo viril y el patriotismo en el siglo XIX}

No se va muy lejos si se toma como referencia central indagar las ideas decimonónicas de la masculinidad y la feminidad. No se discuten las categorías, se es hombre y mujer, macho y hembra, sin más. Y el elemento primordial en la precisión de las nociones de valor y entrega es la Patria, el concepto, la realidad simbólica por las que, con frecuencia, se entrega la vida o se vive sin reservas. No algo distinto se desprende de las anécdotas históricas y el panteón de héroes de los libros de texto. Se desafían el peligro y la muerte porque así se cumplen los compromisos de la hombría, y de la reverencia por la hombría (al valor de las mujeres se le juzga una imitación pálida del coraje masculino). Éstos son los ejemplos: un joven lleva a cuestas un cañoncito a sabiendas que el esfuerzo lo matará; el héroe lanza su arma al otro lado del río y exclama: "Va mi espada en prendas. ¡Voy por ella!"; los Niños Héroes se enfrentan al invasor y uno de ellos, envuelto en la bandera nacional, se lanza desde lo alto del Castillo de Chapultepec; el general Pedro María Anaya apresado por los estadounidenses en Churubusco, al preguntársele por sus rifles y municiones, contesta: " $\mathrm{Si}$ hubiera parque no estarían ustedes aquî"; el liberal Guillermo Prieto, en Guadalajara, se enfrenta al grupo de rebeldes que pretenden ultimar a don Benito Juárez: "Soldados, los valientes no asesinan."

Los actos de coraje se multiplican y a nadie se le ocurre tomarlos por "machismo", como a casi nadie se le ocurre sustentar la violencia doméstica contra las mujeres.

\section{No hay sino dos opciones: $o$ te mueres o te matan (1910-1920)}

Ser macho durante la etapa álgida de la Revolución no es un mérito extraordinario porque todos necesitan serlo, 


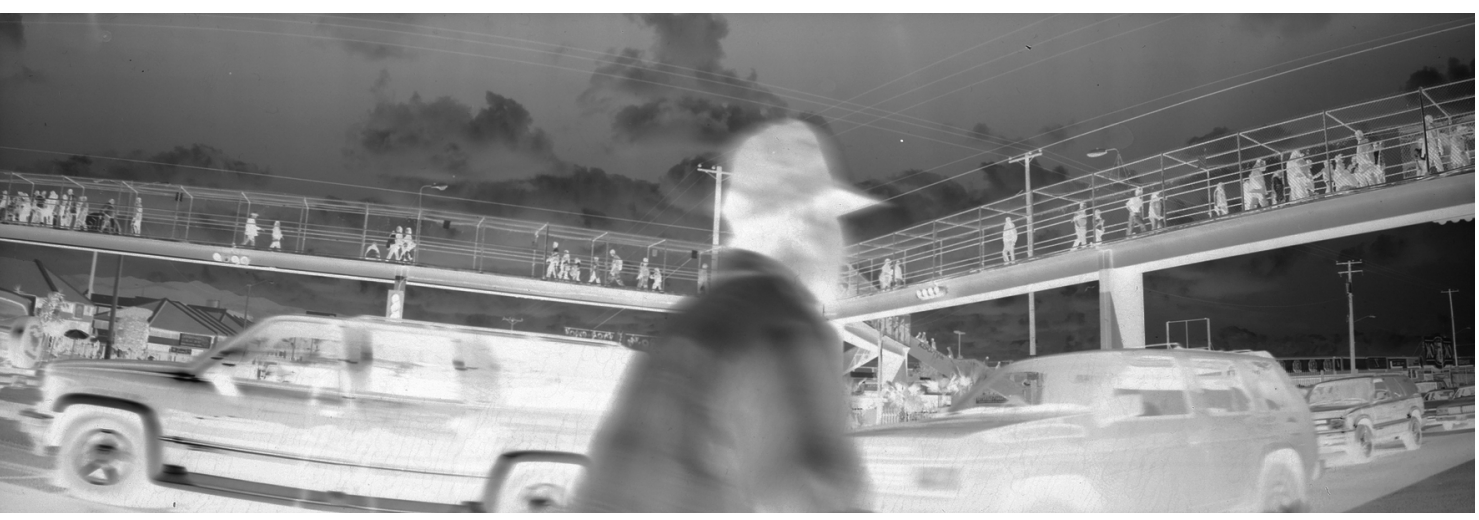

Foto: Arturo Fuentes.

al requerir la sobrevivencia agallas, coraje, güevos. Cantar "Si me han de matar mañana,/ que me maten de una vez", resuelve su condición de bravata teatral y lo hace en vísperas de un combate. Por eso, la escena de la novela de Rafael F. Muñoz, Vámonos con Pancho Villa, es perfecta (es también magnífica la versión fílmica de Fernando de Fuentes). En la cantina de la ciudad tomada, beben tres o cuatro Leones de San Pablo - el grupo de campesinos unido a la Revolufia - y juegan una ruleta rusa. Luego de instantes difíciles sólo queda una bala y el León no retrocede. Está al tanto de lo que le espera y no se arredra. Lo otro sería darle la razón a los cobardes. Y el corrido, el género de la epopeya revolucionaria, es tajante en igualar el "afán revolucionario" con la "indiferencia ante la tragedia personal”. En el “Corrido de Felipe Ángeles”, este general villista, luego de besar la sentencia del Consejo de Guerra, monologa:

-Yo no soy de los cobardes que le temen a la muerte: la muerte no mata a nadie, la matadora es la suerte.

Yo no soy de los cobardes que demuestran su tristeza: a los hombres como yo no se les da en la cabeza...

-Preparen muy bien sus armas y apunten al corazón.
Y el general Benjamín Argumedo ante el pelotón emite su petición:

Oiga usted, mi general, yo también fui hombre valiente, quiero que usted me afusile al público de la gente.

El machismo no es exactamente la Revolución, pero un revolucionario sin siquiera pensarlo, arriesga ese patrimonio fundamental, la vida. Una Revolución crea y disipa la energía mental y emotiva. Dice la canción "La cautela":

Hagamos de cuenta que fuimos basura, vino el remolino y nos alevantó, y cuando estábamos allá en las alturas un golpe de viento nos desapartó.

¿Quién que es no es macho? Entonces el patriarcado es a tal punto determinante que no tiene caso hablar de machismo, y el debate se produce en torno a formas de preservar o arriesgar la vida. ¿Qué se hace ante un pelotón de fusilamiento? ¿Se queda uno impávido y fuma un puro con serenidad, o llora y pide clemencia? La respuesta no tiene sentido porque en vísperas de la muerte las reacciones tienden a unificarse en la pérdida de la moral social del momento y de las características individuales. El desertor se rehúsa a morir por ideas que ya no comparte o no entiende; el campesino se lanza hacia las balas porque la guerra es así, y en los enfrentamientos adopta "el coraje suicida" que no le corresponde al machismo 
sino al relativismo de la lucha, donde el valiente escapa con su cobardía a cuestas. Por eso las mujeres se ven obligadas a machificarse, al grado de convertir su adulterio en tema de peregrinaciones:

Si Adelita se fuera con otro,

la seguiría por tierra y por mar.

Si por mar en un buque de guerra,

si por tierra en un tren militar.

\section{Ahí va el golpe en el diván. "Estoy borracho, les gritaba, y tengo traumas”}

Mientras es una conducta inevitable por muy extendida (y a la inversa), el machismo no es objeto de la crítica. Sólo al irse aislando sus aspectos más "folclóricos" y destructivos (o autodestructivos), se identifica al machismo como tal y un tanto clasistamente, y se ejemplifica con el arrojo suicida en la Revolución Mexicana y en la violencia popular circundada de embriaguez. Los villistas desafían la puntería de los federales, se abren la camisa y gritan: "Péguenle aquí si son tan hombres." Al arrojo popular se le va identificando orgánicamente con el machismo. Así, en El perfil del hombre y la cultura en México, 1934, de Samuel Ramos, se dice:

Aun cuando el "pelado" mexicano sea completamente desgraciado, se consuela con gritar a todo el mundo que tiene "muchos huevos" (así llama a los testículos). Lo importante es advertir que en este órgano no hace residir solamente una especie de potencia, la sexual, sino toda clase de potencia humana. Para el "pelado" un hombre que triunfa en cualquier actividad y en cualquier parte, es porque tiene "muchos huevos". Citaremos otra de sus expresiones favoritas: "Yo soy tu padre", cuya intención es claramente afirmar el predominio. Es seguro que en nuestras sociedades patriarcales el padre es para todo hombre el símbolo del poder. Es preciso advertir también que la obsesión fálica del "pelado" no es comparable a los cultos fálicos, en cuyo fondo yace la idea de la fecundidad y la vida eterna. El falo sugiere al "pelado" la idea del poder. De aquí ha derivado un concepto muy empobrecido del hombre...

Desde la perspectiva actual, lo más ostensible del texto de Ramos no es la hipocresía (ese depositar en los "pela- dos" las características de los hombres de todas las clases sociales), sino el rubor clandestino ya generado por las lecturas iniciales de los textos de Freud, y por la certidumbre del peso muerto de muchas de las tradiciones de "la virilidad", que alientan la ineficacia, la productividad escasa y el retraso educativo y cultural:

Como él (el "pelado") es, en efecto, un ser sin contenido substancial, trata de llenar su vacío con el único valor que está a su alcance: el del macho. Este concepto popular del hombre se ha convertido en un prejuicio funesto para todo mexicano. Cuando éste se compara con el hombre civilizado extranjero y resalta, se consuela del siguiente modo: "Un europeo — dice - tiene la ciencia, el arte, la técnica, etcétera, etcétera; aquí no tenemos nada de esto, pero... somos muy hombres." Hombres en la acepción zoológica de la palabra, es decir, un macho que disfruta toda la potencia animal. El mexicano, amante de ser fanfarrón, cree que esa potencia se demuestra con la valentía. ¡Si supiera que esa valentía es una cortina de humo!

"Something wicked this way comes..." La cita shakesperiana sobre la maldad en las proximidades, describe las primeras consecuencias del encuentro de una sociedad estructurada por la desinformación y los prejuicios con las divulgaciones de Freud. Si ya se ve en la valentía una "cortina de humo" es porque la sobreactuación le pone sitio al orgullo machista. El inconsciente es un pozo de revelaciones, y entre ellas se encuentran las sensaciones de debilidad. Ramos se protege: primero habla del "prejuicio funesto para todo mexicano", y luego vuelve a responsabilizar únicamente al "pelado" y su percepción de la realidad, pero lo que se apunta es el debut del recelo sobre los motivos de la conducta. Por esos años circula profusamente el ensayo del endocrinólogo español Gregorio Marañón sobre Don Juan, donde el donjuanismo, en su insaciabilidad, apenas disimula la inclinación homosexual. Y ya a mediados de la década de 1950, el psicoanálisis deslumbra por la modernidad que le ofrece a la clase media de profesionistas y por su atractivo periodístico. Es una zona "científica y lírica" a la vez, en donde circulan como monedas de cambio los traumas, los actos fallidos, los complejos de Edipo o de inferioridad, los chistes equívocos o repetitivos, y, más que ninguna otra cosa, los sueños antes analizados por la oniromancia y sus variantes. 
¡Qué dicha explorar el subconsciente! ¡Qué terror la posibilidad de una "lesión en el inconsciente!” ¡Qué oportunidad la de ser objeto de una "autopsia del alma"!

Ya en la etapa de la industrialización, el machismo (el término que denuncia o elogia una conducta) se va convirtiendo en "mala palabra", delatadora de actitudes vandálicas y señal de anacronismo sin remedio. (Entonces lo contrario del macho es el varón, término igualmente patriarcal pero más contenido en cuanto a su vocación de arrasamiento.) Si antes de 1960, para poner alguna fecha, sólo excepcionalmente se censura el machismo, luego abundan las críticas a sus vertientes de autoengaño, las bravatas desde la inermidad social y económica, la vanagloria del dinero y el poder, los sueños de grandeza y soberbia. Al machismo se le responsabiliza en gran medida del arraigo nacional en los prejuicios y la intolerancia, del reforzamiento de las causas de la desigualdad. "Si no fuéramos tan machos." Es decir, si nuestra psique no sufriera tantas averías.

“¿Qué me miras, güey? ¿Soy o me parezco?/ Si eres tan hombre, explícame antes de que te mate por qué no traes pistola." El antiguo entusiasmo por la exhibición de impunidades, se va volviendo a ojos de la sociedad la vocación de sordidez, en gran parte por el miedo que le tiene al ridículo la barbarie pintoresca, y en parte también por el avance de las posiciones feministas.

\section{“No me vengas a decir que tu mamá no preparó la cena porque todavía no llega de la maquila"}

No obstante la democratización creciente de la vida cotidiana, el sexismo retiene algunas fortalezas. Anoto algunas de éstas:

- La condición laboral de las mujeres de clases populares se incorpora también, muy opresivamente a parte de su psicología. La falta de resistencia a las inclemencias del patriarcado se nutre de las jornadas de semiesclavitud (examínense los horarios de las maquiladoras en México), de la explotación sexual (los capataces siguen al frente del derecho de pernada), de la anulación de los derechos humanos como se demostró en el caso de las costureras de San Antonio Abad revelado por los terremotos de 1985.

- En la política, por más presidentas de partido que hayan tenido el PRI y el PRD, y por más gobernadoras que se conozcan de Colima y Tlaxcala, y ahora de Zacatecas, por más diputadas y senadoras y secretarias generales y presidentas municipales que se acumulen, la política es todavía espacio patriarcal. Una sola prueba: ¿algún político reconocería en serio la posibilidad de una Presidenta de la República? Con la sutileza que le fue dada, el líder histórico del PAN, Diego Fernández de Cevallos, ante la militante panista que demandaba el sistema de cuotas para mujeres en la representación parlamentaria, cuota ya autorizada por la ley, replicó: "De ninguna manera. Si aprobamos las cuotas para mujeres, terminaremos concediéndolas a los jotos." He aquí la trayectoria del machismo: del Indio Fernández al Criollo Fernández de Cevallos.

- En una nación con 51\% de mujeres en su cuenta demográfica, el gabinete presidencial, reducido o ampliado, apenas dispone de dos de ellas, escasamente significativas en las jerarquías de la atención pública. Y algo similar sucede en los distintos niveles del poder. ¿Qué empresaria famosa existe? La Iglesia católica, ante la exigencia de mujeres en el sacerdocio, exalta el sexismo ordenado por Dios: "Las mujeres no son necesarias en el altar porque ya están los hombres, y Dios hace que los unos actúen por las otras."

- Una variante del "síndrome de Estocolmo" lleva con frecuencia a las víctimas del machismo a colaborar con sus verdugos, impulsadas muchas veces por el clero.

- Los índices altísimos de la violencia intrafamiliar, ligados a los abusos sexuales en el seno de las familias, dan idea de la grosera hegemonía del machismo. "Te golpeo para que no imites el descaro y la coquetería de las vecinas que, viéndolo bien, también se dejan golpear.”

\section{"Y se fue desmoronando como si fuera un montón de piedras" (Pedro Páramo)}

En Los significados del macho, Matthew C. Gutmann, de modo convincente encuentra ya inapropiados y enreda- 
dores los estereotipos del macho mexicano. Tiene razón en la medida en que al transformarse las nociones rígidas de la feminidad, y al valorarse cada vez más las relaciones igualitarias de pareja, el machismo típico y estereotípico se va desintegrando. Ya lavar trastes y pañales, asumir que en las reuniones no haya separación de género ("las muchachas por aquí, / los muchachos por allá, / y sentados en las bancas los papás y las mamás"), hacer cola en las tortillerías, aceptar que la mujer mantenga el hogar, asumir el desarrollo educativo de las mujeres, etcétera, son actividades que indican la metamorfosis implacable. $\mathrm{Si}$ ahora los hombres no lloran es porque están viendo la telenovela de la tarde.

La crueldad con los animales —esa pasión por el "arte taurino" que denota una insensibilidad atroz ante el sufrimiento de seres vivos - es el preámbulo de la crueldad ejercida contra quienes no logran defenderse, y es la plataforma de la perseverancia del machismo. Sí, el ma- cho de clases populares no se deja de nadie luego que se ha dejado de sus patrones, de la policía, de los burócratas. Y es la sensación de impotencia al cabo de tantas bravatas la que impulsa internamente, a través del azoro, las modificaciones crecientes del machismo.

\section{“La habéis dejado imposible/ para vos y para mí"}

Frase de don Luis Mejía, al enterarse de que don Juan Tenorio ya agregó a su colección de virginidades quebrantadas la de doña Ana que él pretendía (véase la obra de José Zorrilla)

Hay un decálogo interminable del machismo ("No pedirás perdón / No fracasarás a menos que quieras desmasculinizarte / No le permitirás a tu cuerpo que use el lenguaje que le dé la gana / No admitirás heterodoxias ni te rendirás ante el chantaje sentimental de las mujeres / No asistirás a cantinas, sobremesas familiares y rincones

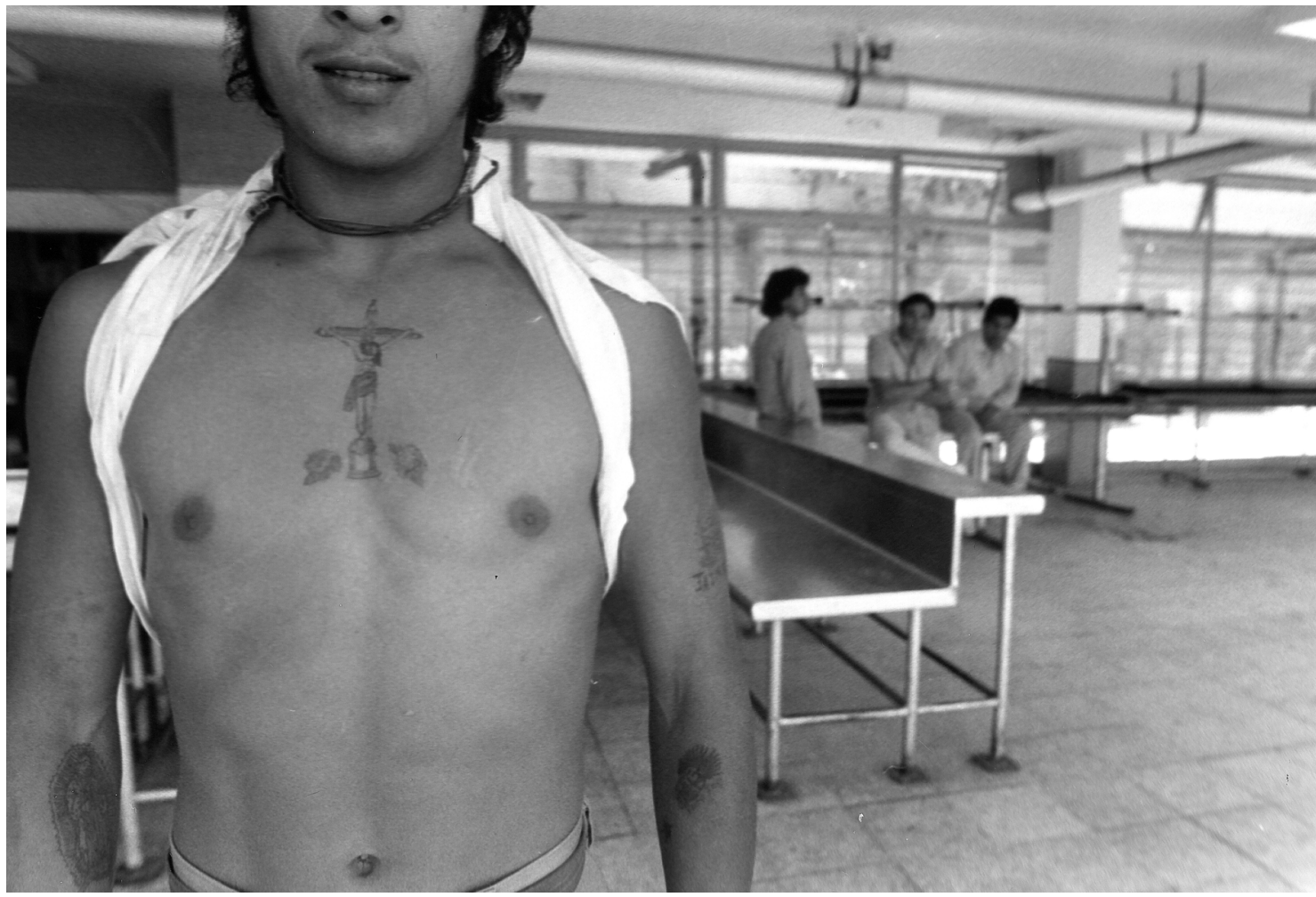

Foto: Arturo Fuentes. 
umbríos de la conciencia sin afirmar que la subordinación la impuso Yahvé, al extraer a Eva de la costilla de Adán”).

Para atrasar la modernidad, en su dimensión de sistemas informativos, debates intelectuales, difusión del pensamiento científico y cancelación de prejuicios, se promueve la ignorancia y se alienta el antiintelectualismo. De allí la demora de las teorías freudianas a México, todavía en la década de 1930 a disposición de unos cuantos en resúmenes vulgares, o bajo el augusto manto de la Psicología del Mexicano (¡ah, las hipótesis donde el componente indígena de la nación es la madre violada por un rudo soldado de Castilla!). Se manda a la sexología a los desvanes de la sordidez y, por un tiempo, la derecha rodea de sospechas y difamaciones los conocimientos que le irritan y perturban.

\section{III}

“Las mujeres / deben ser como todas las potrancas / que se engríen y se amansan con sus dueños / y no saben llevar jinete en ancas"

Canción "El herradero", interpretada en la película Flor Silvestre (1943) por Lucha Reyes

Si cambian la economía, la política y la moral social, se transforman también los cánones de lo femenino y lo masculino, por ser muy distintas las consecuencias y las transformaciones nunca mecánicas de lo íntimo y de lo público; afectan la economía, la política y la moral social. Si la naturaleza humana no es tan modificable, sí varían el comportamiento autoritario y ampliamente las conductas, y tan pertenece a la historia una parte de la psicología que muy probablemente el discurso de bienvenida a la condición femenina del siglo XXI mexicano lo pronuncia el 28 de marzo de 2001 en el Congreso la comandante Esther del EZLN:

Mi nombre es Esther, la comandante Esther... Soy zapatista, pero eso no importa en este momento. Soy indígena y soy mujer, y esto es lo único que importa ahora... También [las mujeres indígenas] sufrimos el desprecio y la marginación desde que nacimos porque no nos cuidan bien. Como somos niñas, piensan que nosotros no valemos, no sabemos pensar ni trabajar, ni cómo vivir nuestra vida.
Por eso muchas de las mujeres somos analfabetas, porque no tuvimos la oportunidad de ir a la escuela.

Y cuando estamos un poco grandes, nuestros padres nos obligan a casar a la fuerza, no importa si no queremos, no nos toman consentimiento. Abusan de nuestra decisión, a nosotros como mujeres nos golpean, nos maltratan nuestros propios esposos o familiares, no podemos decir nada porque nos dicen que no tenemos el derecho de defendernos...

Al cambio de mentalidad lo arraiga la presencia creciente de las mujeres en la vida económica y la enseñanza superior. El feminismo - por las vías múltiples que se desprenden de sus actitudes, movilizaciones, textos e incluso consignas - consolida las exigencias de derechos reproductivos y trato laboral justo mediante seguridades psicológicas y rudimentos teóricos, que se esparcen en la vida laboral, las batallas de las madres solteras, la lucha de las sindicalizadas a favor de igualación salarial y contra el abuso sexual, y, sobre todo, en el cambio gradual de las condiciones hogareñas. Si lo personal no es por fuerza político, lo personal (condición femenina) está muy ligado con el respeto o la falta de respeto a los derechos humanos, y por eso, en última instancia es también político. Y disminuye la resistencia ante el feminismo, salvo - y esta salvedad da idea de las fuerzas del machismo y el patriarcado- en lo tocante a la despenalización del aborto y las exigencias de más amplia representación política. La derecha sólo concede a la fuerza, y todavía en la Conferencia de Mujeres de Beijing, las enviadas de Pro Vida y el clero católico rechazan el término género, porque "traiciona la división natural del mundo entre hombres y mujeres".

En lo tocante al aborto, no se cede en lo mínimo. A los conservadores, empeñados en cancelar la noción misma de derechos femeninos o en reducirlos a frases vacías de todo contenido, el aborto les resulta simplemente asesinato porque eso le parece al Vaticano. No los conmueve la mención de los cientos de miles de abortos anuales, ni de las muertes causadas por las condiciones terribles de los abortos en clínicas clandestinas ni de los instrumentos punzocortantes que usan mujeres desesperadas, ni del derecho reproductivo. "Dios prohíbe el aborto", se asegura, y los obispos y sus aliados dan por concluido el de- 
bate. Pero éste sigue y por ráfagas se filtra en la televisión y en algunas universidades privadas, y si la fuerza coaligada del clero católico, la derecha política y sus aliados en el gobierno obstaculiza los procesos legales, en los grandes centros urbanos - para empezar- disminuyen los sentimientos de culpa y de vergüenza personal y familiar asociados tradicionalmente con el aborto.

El afán de anular la modernidad se da en la batalla jurídica y en la abolición de las discusiones hasta grados de ignominia. En 1992, el obispo de León, Rafael García González, presiona al presidente municipal panista para cancelar en la Casa de la Cultura la conferencia sobre aborto de GIRE (Grupo de Información sobre Reproducción Elegida) y de Católicas por el Derecho a Decidir. Con violencia, un grupo de mujeres panistas, junto con el secretario particular del obispo, impiden que el acto se efectúe en un local privado. En 1993 en Chihuahua, la mayoría panista en la Cámara de Diputados local reforma la Constitución del estado para ampliar el derecho a la vida "desde el momento de la concepción". Se derogan las causas de impunidad previstas en el artículo 219 del Código Penal estatal: imprudencia, violencia, inseminación artificial no deseada y peligro de muerte de la madre. El dogmatismo cumple brevemente sus ideales de exterminio. Luego, en este caso específico acepta la derrota.

\section{Si cambia el estatus de las mujeres, la masculinidad se modifica}

Contener a la modernidad en las relaciones entre los géneros tiene un objetivo obvio: posponer hasta cuando se pueda el ejercicio pleno de los derechos. Sólo la inundación de divulgaciones freudianas y manuales de sexología, el incremento de viajes de mexicanos a Europa y Estados Unidos, y el cambio cultural provocado por las oleadas migratorias, limita o desaparece la insistencia en el recato $y$ el pudor.

También, y como fenómeno central, las mujeres se van independizando de maridos, padres, confesores, moralistas y de la noción religiosa que aborrece al sexo únicamente placentero. Desaparece casi por entero la situación descrita por Flandrin, que Weeks cita: "La pareja no esta- ba sola en su lecho matrimonial: la sombra del confesor asomaba entre sus retozos." Se produce una gran revolución cultural: la emergencia del feminismo. Antes, el panorama es de exclusión absoluta. En el primer siglo del México Independiente, la ética que comparten liberales y conservadores confina a la mujer en "el hogar", sin acceso posible al nuevo Estado-nación. Ni en la Constitución de la República de 1857 ni en la Constitución de 1917 hay reconocimientos de importancia de la igualdad ante la ley de las mujeres, pese a hechos excéntricos como el Primer Congreso Feminista en Yucatán en 1916, promovido por el gobernador Salvador Alvarado. Y las mujeres sólo se agregan formalmente a la República en 1953 cuando Ruiz Cortines, seguro de la alianza con la Iglesia católica, se muestra magnánimo con "las féminas" y les concede el voto, que ejercen por vez primera en 1955. Los representantes de la Familia y el alto clero insisten en las brumas de ignorancia para las mujeres, y, en rigor, la inserción más genuina es posterior, al masificarse la presencia femenina en el aparato productivo.

En el Año Internacional de la Mujer, el gobierno mexicano no acierta a reconocer las razones feministas. Esto le lleva más tiempo. Al principio, cree responder al fenómeno con la incorporación selectiva (el tokenism), las escasas "delegadas plenipotenciarias" del género, trasladadas a la administración pública por su representatividad biológica-ideológica. A fines del sexenio de José López Portillo, y casi por ley, se sabe del repertorio admitido: una gobernadora, una secretaria de Estado, varias senadoras, diputadas y presidentas municipales, etcétera, etcétera. El discurso oficial se reelabora un tanto, para eliminar las fórmulas más bochornosas del priismo histórico con su "caballerosidad y respeto hacia la mujer sublime, la mano que mece la cuna y mece al mundo", y sin ir más allá de la timidez cognoscitiva de Miguel de la Madrid: "Si bien la Revolución Mexicana ha sido capaz de consagrar el principio y la normatividad de la igualdad (entre hombres y mujeres), la realidad está lejana del principio político y de la norma jurídica."

En la década de 1970, el ánimo feminista en la ciudad de México es imaginativo y belicoso. Sin aviso previo, no más de dos mil mujeres marchan con júbilo, se hacen presentes en los medios liberales y de izquierda, le añaden térmi- 
nos y puntos de vista a los sectores ilustrados y/o militantes, se divierten, consignan su indignación en mantas, artículos, documentales, canciones infestadas de mensajes, obras de teatro, relecturas de la historia y la literatura. La capital consiente esta rebeldía, difícil de observar pero que ya corresponde al estado de ánimo de un sector amplio ("La idea cuyo tiempo ha llegado"). En el resto del país el proceso es más difícil, y son proezas inadvertidas las actividades de colectivos feministas en Puebla, Morelia, León, Durango, Colima, Tijuana o San Cristóbal de las Casas. Sin embargo, no hay dudas: el feminismo no es "moda de importación", y se "nacionaliza", así persista la observación minuciosa de los movimientos europeos y norteamericanos, con su programa de reivindicaciones a corto, mediano y largo plazo, sus tesis múltiples sobre la condición femenina y su acoso al heterosexismo y el chovinismo masculino. Un término se implementa: sexismo.

\section{IV}

\section{La sociedad: el pudor que ya no quiere ser mencionado por su nombre}

Todo se intenta: campañas a favor de los Verdaderos Valores (no se especifican, no hacen falta); restauraciones de la Familia (con el padre hablando solo en la cabecera de la mesa, de otro modo no es familia, a lo sumo una tribu desdichada que se educa en la desintegración); censura en el cine (exitosa por cuatro décadas) y en la televisión (lograda a medias); arrebatos contra el hedonismo de la sociedad contemporánea (no se define ni se describe al hedonismo, provocaría la excitación); embestidas contra el condón hasta el amanecer de la impotencia; amenazas de excomunión repartidas en varios frentes de batalla; oposición virulenta a la educación sexual y el control de la natalidad... El sexo no nada más ya no es secreto: también está de moda, lo que exige y con fruición politizada, la difusión de los detalles. ¡Ah, la última ratio de la fellatio!

Sin el silencio que asfixie o distorsione al gran objeto de su inquina, la derecha está a la defensiva. Flotan a la deriva sus instrumentos de erradicación del Mal: la voz baja (ante Lo Inmencionable, la voz muy alta al deman- dar castigo para Lo Innmencionable), las alusiones crispadas, el ceño que imita a Jehová cuando se ofendía por la persistencia del pecado (así debió ocurrir), la ronda del pudor lastimado. Lo explícito corrompe las costumbres, y enronquece el gemido protector de la derecha: “ $¡$ De eso no se habla en mi presencia!” ¿A quién se intimida ahora con la consigna "Si quieres seguir con ese tema, vete a la porqueriza"? En las discusiones familiares la mención del sexo oral se naturaliza al punto de eliminar para siempre el sonrojo, y Bill Clinton y Monica Lewinsky, los Adán y Eva de las revelaciones por Internet, son algo más que un gran escándalo, son la puerta abierta de la normalización del morbo. Desaparecen los chismosos; de hoy en adelante y a propósito de cualquier tema sexual, todos somos Fiscales Especiales.

Déselo al Viagra y a su fastuosa comercialización, el sitio infernal que merece. ¿Quién suprime ahora la indiferencia enumerativa o el sarcasmo a propósito del sexo, de las disfunciones eréctiles, de la inapetencia entre casados, del ridículo ante las sexoservidoras, del gemido del deseo

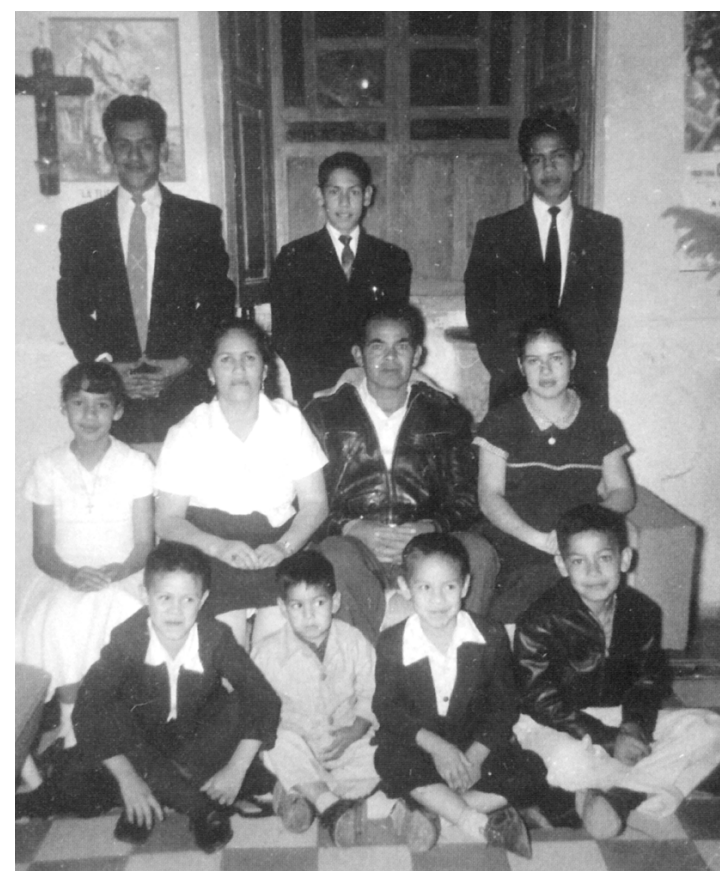

Década de 1940. Calendario Coriac 2000 / Cortesía de Coriac. 
convertido en departamento de quejas por canalladas de la fisiología? Con el Viagra, los males de la genitalidad se vocean entre las preocupaciones de las transnacionales. Si el cuerpo ya no dispone de secretos, se jubilan internacionalmente por varias de las obsesiones centrales de la derecha.

Transmitida como chisme, la divulgación sexológica es la moda interminable. "Cómo erradicar la frigidez / Goce cada segundo los Siete Minutos / Erotice su trato sin renunciar a su vida espiritual / Recuerde que la castidad no es una "enfermedad de mujeres" sino el castigo por no ir al gimnasio / No admita que la impotencia es la venganza de la carne ante las fragilidades del alma..." En las revistas femeninas se examinan sin censura los temas cuyo comentario hace treinta años habría causado la expulsión del hogar. Y agréguense la psicología posfreudiana, las terapias de grupo, la sexología que-sípuede-entrar-a-su-hogar (casi toda), el crecimiento de las divulgaciones médicas, los avances de la ciencia, la educación sexual en las primarias y secundarias, el cine contemporáneo, la derrota de los censores de la apariencia (a funcionarios menores del gobierno de la ciudad de México, que intentaron por una hora prohibir la minifalda en unas oficinas, se les cesó en el acto), los programas especiales y los debates televisivos sobre sexo. Y lo que las series estadounidenses traen consigo, la mezcla de sentido del humor y franqueza sexual, la visión del coito como otro escenario de la intimidad o de lo que deja de ser la intimidad. Constituyen fenómenos internacionales Sex and the City y Queer as Folk, para citar ejemplos paradigmáticos.

Falta por anotarse la masificación del "exhibicionismo" o como se les diga a las nuevas actitudes sobre la corporalidad de hombres y mujeres jóvenes, que duplican por doquier en fotos artísticas, en la publicidad de los espectaculares que promulga la deseabilidad del cuerpo construido a pulso (Calvin Klein, por ejemplo, es el gran auspiciador de los gimnasios), en las películas y los programas de televisión, en los concursos de belleza. Si todavía se protege "el último pudor" (el desnudo frontal), lo demás está tan a la vista que el pecado contemporáneo por antonomasia no es el exhibicionismo sino la celulitis.
Tradicionalmente, las "malas palabras", los vocablos y las expresiones de la obscenidad, vivían en el infierno semántico por su relación incestuosa con el sexo. Eran los términos del "sólo para hombres", del aprendizaje de lo sexual a través de la vulgaridad lingüística, del reservarle a las conversaciones sin remilgos la función de nicho ecológico de la masculinidad sin tacha... Por eso, la difusión aparatosa de lo sexual, más que ningún otro elemento, aniquila la razón de ser de las malas palabras. Si se dicen por doquier, si el habla unisex es irreversible, no es únicamente por la inutilidad de mantener zonas del tabú, sino porque las "obscenidades" van resultando tímidas de tan gastadas, meramente descriptivas o incomprensibles. La represión de las "groserías", a fin de cuentas, no era sino la estratagema que retenía al sexo en la oscuridad. Arrinconar en la herejía a unos cuantos vocablos era el método para volver inmencionables las funciones aludidas. Si el sexo sale a la calle y se exhibe en las sobremesas de las familias decentes, las "obscenidades" envejecen sin remedio, convertidas en pintoresquismo.

Hoy, el chiste, el dirty joke, es el método más implacable de la reprobación moral. El moralismo, desprestigiado al extremo, ya es mala palabra, y quien inicie sus comentarios diciendo: "Yo jamás he sido infiel a mi mujer", ha tirado por la borda su discurso, convocando de paso al psicólogo o psicoanalista que hoy ya todos llevamos dentro. El adulterio todavía propicia desdichas, pero ya se liga más al costo de los juicios de divorcio que a crímenes suscitados por la defensa de la honra. En cambio, el chiste es la forma triunfalista de celebrar la caída del adúltero, es decir, para ser exactos, del incapaz de impedir la adquisición "de los cuernos". Si el sermón delata, el chiste descubre. Del regaño moralista se va camino al perdón; del chiste sólo se sale al ridículo.

Desde siempre, el chiste ha sido el liquidador del totalitarismo de la derecha y sus muros de silencio. En épocas de auge de la Liga de la Decencia y de las asociaciones belicosas de padres de familia, los chistes de Pepito (la sexualización de la infancia) y los "chistes colorados" en general, hicieron las veces de voces críticas de la sociedad, tal era el tamaño de la represión. Tradicionalmente, el chiste era la gran educación sexual al alcance, y en sólo 
una década, la difusión sexológica despoja a estos gracejos de su filo transgresor y los deja como fábulas cotidianas ("Calláte che, que vos también tenés tu historia"). Dejan de ser incursiones (a carcajadas) en las tinieblas, y esto explica el auge de los chistes posfreudianos, donde los traumas son el punto de partida. Y algo similar le sucede a los albures, esos interminables juegos de palabras cuyo mérito es la "posesión sexual" del adversario. Entre el sida y la disminución de cargas ideológicas y de prejuicios sobre la homosexualidad, el albur se configura como un deleite típico de candidatos a la jubilación.

El morbo, si se difunde por internet, se hace acreedor de las bendiciones de la tecnología, y deja de ser morbo para transformarse en información de valor agregado.

Un lugar común ya incluido en las tradiciones nacionales, avisa del doble rostro de la sociedad mexicana: la solemnidad moralista que oculta el desenfreno orgiástico, las actitudes licenciosas que se redimen los domingos en misa. El culto a la hipocresía es históricamente cierto, pero a estas alturas requiere de matices porque el criterio dogmático a ultranza ya es sólo efectivo en el territorio de los estrictamente creyentes, y no alcanza a los demás sectores de la sociedad. Dicho en otras palabras, la sexofobia es un privilegio del sector integrista.

El moralismo, socialmente, dista de contar con la aprobación mayoritaria. Una prueba contundente se vive en la ciudad de México en las elecciones de 1997. El candidato del partido de la derecha, Acción Nacional (PAN), cuestionó el uso del condón porque, dijo, amenazaba a la ecología y en especial a los sistemas de drenaje. Esto, unido a las prácticas conservadoras de los alcaldes del PAN (prohibición de minifaldas, cierre de obras teatrales, suspensión de exposiciones de desnudos femeninos, entrada de la policía municipal de Guadalajara a un albergue de enfermos de sida porque allí se impartían talleres de sexo seguro, arresto de cuatro mujeres activistas anti-sida en Ciudad Juárez por pegar posters de una campaña de prevención, declaraciones sexistas y homófobas de sus candidatos, prohibición de Semanas Culturales Lésbico-Gays en Veracruz y Jalapa, etcétera), ayudó poderosamente a la derrota mayúscula del candidato del PAN, lo que el partido mismo reconoció en su análisis de la campaña, al situar las reacciones contra el moralismo como su primer problema.

Ejemplos de apertura y liberalización abundan, pero, ¿autorizan a declarar cosa del pasado a la doble moral? Seguramente no, pesa el tradicionalismo en la política y en la vida de las clases adineradas, y el anhelo de respetabilidad suspende, atenúa o desvía campañas fundamentales (control de la natalidad, prevención del sida, educación sexual), y detiene con furia los intentos de despenalización del aborto. Vivimos una irrealidad que sería operática si no fuera circense: el tradicionalismo quiere imponer una moral y unas buenas costumbres ignoradas y/o rechazadas por la gran mayoría, pero los políticos insisten en concederle estatus de mayoría absoluta a una minoría decreciente porque retiene los bastiones de la formación de la clase en el poder. Ésta ha sido la consigna: si educo a la élite en la hipocresía y en las ideas fundamentalistas de la respetabilidad, mantengo el control y aplazo las victorias liberales de la secularización.

Si confiamos en encuestas muy diversas de los años recientes, en las grandes ciudades el fundamentalismo está arrinconado: se produce ya la despenalización moral del aborto (no la aprobación moral, cosa muy distinta, sólo el dejar de juzgar como criminales a quienes lo hacen); el machismo está en retirada, y sus plazas fuertes dependen en gran medida del atraso educativo de las mujeres; la homofobia y el sexismo son las nuevas malas palabras; cada vez más la pérdida de la virginidad antes del matrimonio es asunto de las estadísticas, y no de los aullidos de furia paterna seguidos de la búsqueda armada de la reparación de la honra; el elemento perturbador en los coitos no es la conciencia del pecado sino el sexo seguro.

Lo anterior, insisto, matiza considerablemente la idea clásica o típica de la doble moral. Ahora, hay de modo comprobable una triple moral: la tradicionalista, la de la práctica y la de las encuestas. Esta última, desde su feliz o desdichado anonimato, insiste en hallar inaceptables a las dos primeras, pero carece por razones obvias del impulso, la decisión organizativa y la oportunidad de intervenir en la vida pública, salvo en casos excepcionales 
(la primera, la humillación programada de las mujeres), los códigos de represión e inhibición del deseo, las tradiciones que dividen "el cuerpo y el alma", la misoginia como recurso clerical y patriarcal, la sacralización de las tácticas represivas de la familia. Con préstamos de la antropología social y la sociología, la historia de la sexualidad modifica considerablemente las "sorprendentes noticias" sobre zonas muy profundas de las personas y las sociedades.

\section{“Ni siquiera me enteré de mi desinformación"}

Las limitaciones de la enseñanza actúan invariablemente a favor del tradicionalismo. En materia de educación sexual casi todo el siglo XX se pierde en responder, desde el acoso, a las campañas clericales contra la libertad de enseñanza en las escuelas públicas. La derecha no anula el desarrollo pero ansía cancelar la capacidad de elección. "Que nadie aproveche el progreso para sentirse libre." Y un aliado duradero del antiintelectualismo es la superficialidad que, verbigracia, convierte en chacota lo captado de modo insuficiente. A los traumas y el inconsciente se les menciona con alegre descuido, y del psicoanálisis se extraen por lo común gracejos sobre el diván y el ocio de las señoras ricas. La ausencia social de la cultura científica disipa en gran medida las ventajas de los hallazgos freudianos y posfreudianos, aplicados con frecuencia al morbo de nota roja: "Los traumas de infancia repercutieron en el feroz criminal / El estrangulador Goyo Cárdenas mató por no resolver bien su sexualidad". Pero la vida de la mente y, sobre todo, las fantasías, revelan la diversidad del deseo. "En la vida privada de la mente nada es seguro, nada es fijo." Exactamente lo opuesto de las creencias según las cuales la subordinación sexual de las mujeres resulta de su inferioridad mental y moral. En una cultura fundada en la arrogancia patriarcal, la sexualidad es la comprobación de las funciones invariables y eternas del hombre sobre la tierra, lo contrario del fluir constante. Según el conservadurismo, algunas de cuyas premisas sobre sexualidad comparten los sectores liberales y de izquierda, no sólo la investigación sexual es "moralmente sospechosa”, también, lo central del sexo es la intensidad de la reproducción o, ya en confianza, el relato de las proezas masculinas.

El sexo es lo innombrable, lo transformable en cursilería o procacidad, lo oculto entre las sombras. No sólo se retarda la actualización del conocimiento científico, también se institucionalizan las culpas de espectadores y lectores, se iguala con el pecado la urgencia de estar al día. Debates importantísimos se observan de lejos, privilegio de unos cuantos, y lo que se filtra suele adquirir carta de ciudadanía cultural por las variantes del chisme (“ $¿ Y a$ te dijeron que la libido es asunto de todos?").

"La manera en que pensamos el sexo modela nuestra forma de vivirlo", afirma Weeks. Si esto es así hasta fechas muy cercanas, las ideas dominantes sobre el sexo en México le confieren varias de estas funciones:

- Deber familiar ante Dios y los hombres que sólo halla gozo en el placer de la reproducción.

- Oportunidad del pecado que ratifica la confianza en los derechos del machismo, sustentados en las absoluciones luego de la confesión.

- Señal de la superioridad indudable y eterna del Hombre sobre la Mujer.

- Concesión de un acto común y corriente en la hazaña personal que al multiplicarse magnifica la idea de sí mismos de los machos.

- Sordidez irresistible, inmersión en los sótanos de la conducta (una vez más la censura y el morbo le confieren dimensiones deleitosas a lo normal).

Desde esta perspectiva, casi todo lo relativo al sexo es antinatural.

\section{Hambre de soledad padece el coito}

Isolda, Isolda, cuántos kilómetros nos separan, cuántos sexos entre tú y yo.

VICENTE HUIDOBRO

Noticiero del cambio. Para la década de 1990 el psicoanálisis ya no es moda social y lo cercan las polémicas sobre "ajustes" a la realidad o "sanos desajustes" y actualizacio- 
nes lacanianas; la sexología avanza, con el auge relativo de Masters y Johnson o sexólogos cuantitativos de esa índole, y su vocabulario se nacionaliza sin riesgo alguno de conocimiento genuino ("sólo los traumas te ayudan a no tener problemas sexuales"); la familia nuclear se comunica con la familia tribal cuatro veces al año (Navidad, cumpleaños, enfermedades, encuentros por azar); las crisis económicas promueven el control de la natalidad por encima de las fulminaciones religiosas; el lenguaje cínico o clínico exhibe al amor como la mezcla de ganas fornicatorias y autoestima; los burdeles son especies en extinción; ni el divorcio ni el adulterio son ya causa formal de escándalo, y un divorciado llega a la Presidencia; es irreversible la participación de las mujeres en casi todos los campos; "hacer el amor" ya no es sinónimo de coger sino de "relación significativa entre dos seres humanos"; son poquísimas las "malas palabras" que sobreviven a su nivelación moral (su uso indiferente). Item más: en función de la generación a que se pertenezca, todo lo preside la nostalgia del sentimiento de culpa o la incomprensión de cualquier nostalgia.

¿Qué ocurre de 1968 a 2004? ¿Cómo se debilitan o cómo ceden las fortalezas tradicionales? ¿A qué atribuir el crecimiento de la tolerancia en asuntos de la moral social? Hay razones diversas (culturales, económicas, políticas, comerciales), pero la causa fundamental de los cambios es la hondura de la secularización. Al no ser $-\mathrm{y}$ desde hace bastante- el sentimiento religioso el eje de las decisiones, pocos repiten convencidos la frase de San Jerónimo: "Adúltero es también el que ama con excesivo ardor a su mujer."

Para la mayoría, la religión es sólo un fragmento de la visión del mundo, indispensable y muy formativo pero no determinante en la vida cotidiana. A este respecto, cada feligrés acumula las pequeñas y grandes desobediencias a las ordenanzas eclesiásticas que los obispos traducen como "la descatolización de México, fruto de la atroz educación laica". De hecho, ocurre sin demasiados contratiempos esa "muerte de Dios", que es el canje de la moral que (como sea) se practica por la moral que únicamente se proclama. (Antes de que cunda la cautela demográfica el número de hijos anuncia el respeto a la moral tradicional: seis, ocho están bien, Dios proveerá.) Y como siempre y en todas partes, la religión es, en lo social, un tributo formal a los ancestros, y un elemento clave en el juego de la Respetabilidad. Luego, en medio de la crisis de la conciencia individual, los sectores con aspiraciones de modernidad esquivan "el soborno del cielo" (G. B. Shaw), observan con indiferencia la "memorización teológica" del sentido de la vida humana y aceptan la relativización de los valores morales en que fueron educados.

La televisión aporta, con eficacia, un argumento persuasivo: "lo indebido" es lo que no está de moda, no hay comportamiento que no atraiga a alguien en algún lugar del mundo y quien seriamente se escandaliza ante lo real (que es legal y legítimo) pierde tiempo, y deja de entender lo que contempla. Y a la provincia la modifican los signos de identidad de "lo moderno". Un país muy fragmentado ingresa a lo homogéneo.

También, por lo menos desde 1920, las metamorfosis de la moral social norteamericana se estudian con avidez en México. Y a cualquier conducta "liberal" o "liberalizada" que surge en Estados Unidos la rodea primero la alarma, luego la burla, en seguida la imitación, y finalmente la asimilación. El proceso se repite: los grupos tradicionalistas se enfrentan a las innovaciones (libertad de opción sexual de las mujeres, uso de anticonceptivos, liberalización de la familia, desnudos frontales en cine y teatro, uso público del lenguaje "obsceno", etcétera); las autoridades dudan o tienen miedo; por un tiempo se consigue la prohibición o el veto, y luego, de manera natural, la innovación se generaliza sin que ya nadie proteste.

A esto se añaden fenómenos motivados por la pobreza, entre ellos la unión libre, la práctica de cientos de miles de parejas, sin dinero para los gastos cuantiosos, en términos relativos o absolutos del matrimonio civil y eclesiástico.

\section{VII}

\section{La homofobia: la fortaleza de la masculinidad ortodoxa}

En 1954, un maestro de la preparatoria, al explicarnos las posibilidades de la metáfora, nos dijo unos versos que inevitablemente memoricé: 
Pobre del hombre que nació mujer, más le valiera pegarse un tiro por doquier.

Por esas fechas leí a Renato Leduc, un poeta excelente y un homófobo de tiempo completo:

Hay gran copia de efebos cuya impudicia aterra, $\mathrm{y}$ dicen que son males que trajo la posguerra.

Lo típico en ese tiempo es dar por sentada la inferioridad natural, o, mejor, la inhumanidad evidente del homosexual, alguien que, al practicar el sexo con sus semejantes, se despoja de toda virtud posible, y, en el mejor de los casos merece esa forma del perdón que es el choteo. Antes de 1990 es inimaginable el término homofobia, ya que, entonces todos, incluyendo los gays, son homófobos. Pinche puto es la descalificación última, y si se usa maricón como sinónimo de cobarde es porque la cobardía traiciona también a la virilidad. No en balde Octavio Paz, en su gran poema "Piedra de Sol”, escribe: “...el sodomita / que lleva por clavel en la solapa / un gargajo”.

Insisto. El término homofobia circula con fluidez al reconocer un sector amplio lo monstruoso de discriminar sobre la única base de las legítimas preferencias sexuales. Antes todo es opresivo, deshumanizador. En 1932, Renato Leduc no es homófobo cuando escribe en Los banquetes: "Porque al fin y al cabo el uranismo no es más que una de tantas éticas, una de tantas actitudes frente a la vida; es, por decirlo así, la actitud a gatas frente a la vida." $Y$ añade, en un rapto de entusiasmo:

Ahora bien, puede afirmarse que la pederastía, como en el Derecho Romano la esclavitud, se adquiere con el nacimiento o por un hecho posterior, precisamente posterior, al nacimiento.

Pero los pederastas congénitos son, casi por definición, invertidos, anormales, enfermos y los otros son siempre ancianos impotentes o jóvenes degenerados cuya virilidad atrofiada no les deja otro recurso que recibir lo que ya no son capaces de dar.

Leduc, por supuesto, no está solo. Así por ejemplo, otro poeta extraordinario, Efraín Huerta, en su "Declaración de odio", se permite estas líneas:



Foto: Arturo Fuentes.

Te declaramos nuestro odio, magnífica ciudad. A ti, a tus tristes y vulgarísimos burgueses, a tus chicas de aire, caramelos y films americanos, a tus juventudes icecream rellenas de basura, a tus desenfrenados maricones que devastan las escuelas, la plaza Garibaldi,

la viva y venenosa calle de San Juan de Letrán.

Depreciar al "desenfrenado maricón" es parte de la estrategia histórica que más que identificar la homosexualidad, como señalan los partidarios de la Teoría Queer, construye el paradigma heterosexual. Éste sería el mensaje: si localizo a los seres abyectos, ubico el perfil de los seres virtuosos, los únicos que en rigor son seres humanos, entre ellos y en primer lugar, yo mismo. A la homosexualidad (la conducta tanto más satanizada cuanto más imaginada) se le hacen cumplir funciones de espejo negro en donde los en verdad humanos jamás se reflejarán. 




Foto: Arturo Fuentes.

El hecho inaugural de esta reducción de un sector significativo a la caricatura es la redada de noviembre de 1901 en la ciudad de México, conocida como el Baile de los 41 porque, según la leyenda, la policía detiene a 42 maricones, la mitad disfrazados de mujeres, y uno de ellos logra huir, don Ignacio de la Torre, yerno del dictador Porfirio Díaz. A partir de ese momento, y casi como si se tratase de la inauguración formal de la especie, los homosexuales (los jotos) existen y sólo se les concibe como afeminados y travestis. A propósito de los gays y durante más de medio siglo, nada tiene tal repercusión en el imaginario colectivo como el Baile de los 41.

¿Tiene sentido calificar de homófoba a la sociedad de 1901 o a la de 1940, que ve natural el envío de homosexuales al penal de las Islas Marías, tan sólo porque con sus afeites y sus trapos de mujer "atentan contra la moral y las buenas costumbres"? El uso de homofobia viene de un movimiento internacional de rechazo de la discriminación violenta (física, laboral, familiar, social), y mientras esto no se produce, no se califica al buen Jehová de homófobo porque ordena la destrucción ígnea de Sodoma, ni lo es Emiliano Zapata, cuya furia al enterarse de la homosexualidad de su lugarteniente Manuel Palafox es tan absoluta que está a punto de fusilarlo. La homofobia se establece con claridad cuando ya no se admiten los odios irracionales.

En la primera mitad del siglo XX, y casi hasta la década de 1970, lo usual es la penalización de los gays. Sin motivo alguno, con el solo argumento de las faltas a la moral y las buenas costumbres, los homosexuales (los jotos, para ser más específicos), son enviados a la cárcel, por ejemplo, a la célebre crujía J de Lecumberri, sin juicio, sin sentencia, sin abogado defensor de oficio siquiera. ¿Quiénes son? Menos que nadie.

Esto alcanza su límite con los asesinatos de homosexuales, tan prodigados a lo largo del siglo, y tan caracterizados por la extrema violencia, el número desproporcionado de golpes y puñaladas, la saña ejercida contra la víctima y su cadáver. Son crímenes de odio porque el asesino liquida al ser de otra especie, al que previamente desconocía. Al ocurrir el crimen, ni la policía, ni el Ministerio Público, ni las familias afectadas en muchísimas ocasiones, se consideran en rigor ante un delito grave, sino ante un suceso de "índole moral". Así, hasta hace muy pocos años, la frase más repetida entre los muy escasos asesinos a quienes sí se apresaba, daba razón de la ideología machista: "Lo maté porque se lo merecía."

\section{Las dudas como certidumbres}

El Informe Kinsey sobre la conducta sexual de los hombres, de 1948, le allega a la posguerra su primer espacio de perplejidad. Alfred Kinsey señala:

Biólogos y psicólogos que han aceptado la doctrina de que la única función natural del sexo es la reproducción, simplemente ignoran la existencia de una actividad sexual no reproductiva. Le atribuyen las respuestas heterosexuales a una parte del equipo innato, "instintivo de un animal", y ven en todos los tipos de actividad sexual a "perversiones" de los "instintos normales". Sin embargo, tales interpretaciones son míticas. 


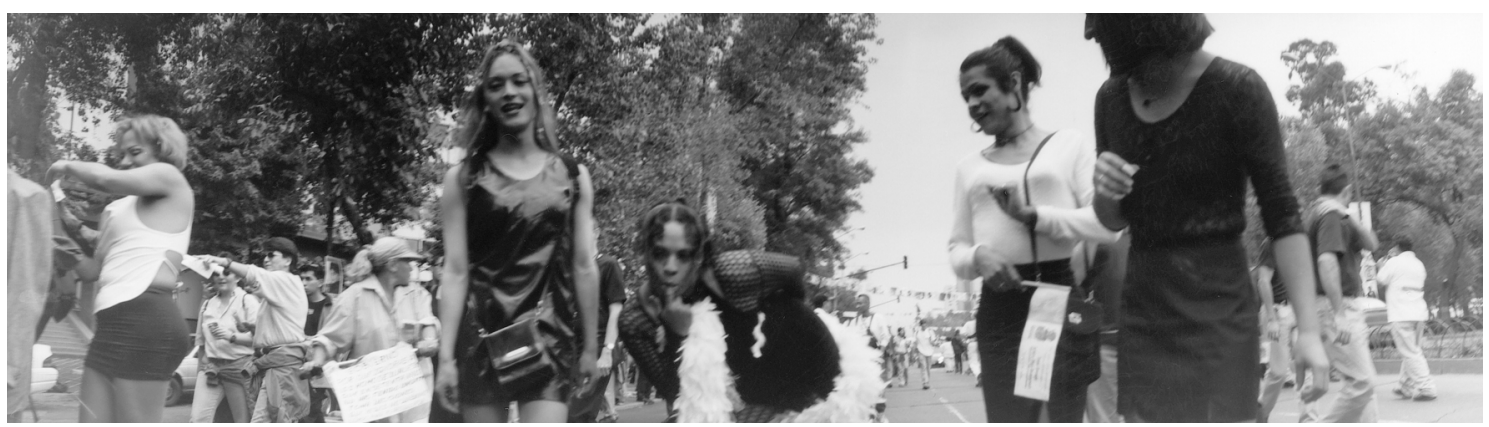

Foto: Arturo Fuentes.

A la distinción entonces categórica entre lo "natural" y lo "antinatural", Kinsey le enfrenta estadísticas que van minando las certezas clásicas. De los encuestados, 35\% ha tenido alguna experiencia homosexual, y cerca de $10 \%$ practica regularmente la homosexualidad. La revelación es asimilada dificultosamente, pero en México el Informe Kinsey no se divulga por las razones acostumbradas: incredulidad ante otros comportamientos sexuales, certeza del carácter disoluto de la sociedad estadounidense, miedo a reconocer el perfil de una pesadilla.

Históricamente, la homofobia se localiza al establecerse en el plano internacional la conciencia de los derechos de las minorías, y esto en fecha tan reciente como la década de 1970. Y en este sentido, por homofobia no se entiende las antipatías o las desconfianzas o los recelos morales que los gays suscitan, algo inevitable por enraizado y de muy difícil eliminación, incluso entre los propios gays, sino la movilización activa del prejuicio, la beligerancia que cancela derechos y procede a partir de la negación radical de la humanidad de los disidentes sexuales, negación estimulada por el atraso y el fanatismo. Pongo el ejemplo de un político del PAN, que, curiosamente, presidió en el Senado la Comisión de Cultura. El 17 de agosto de 1995, en La Jornada, Mauricio Fernández Garza afirma: "Volviendo al caso de la cultura, yo conozco muchísimos artistas que por lo que tú quieras, por razones que desconozco, el hecho de que tengan un grado mayor de hormonas femeninas les da unas sensibilidades encabronadas como artistas. Porque es uno de los ambientes en que coincide mucha gente; más que pensar que son jotos, se piensa que nacieron con una sensibilidad maravi- llosa... Cada grupo debe estar con los suyos: los católicos con los católicos, los budistas con los budistas, los jotos con los jotos, y tú ya sabes en dónde es tu lugar... No debe haber censura, pero sí una clasificación."

Qué bueno que no pidió la reunión de los atrasados con los atrasados, porque eso sería violar el derecho de tránsito de los homófobos. El 26 de junio de 1995, el ayuntamiento panista de Mérida promulga su Reglamento de Espectáculos Públicos, donde se exige "respetar los tradicionales valores culturales, intelectuales, éticos, religiosos y artísticos característicos del pueblo yucateco, así como el respeto a la intimidad de las personas, a la genitalidad, a la sexualidad, el debido decoro que le corresponde a la reproducción del género humano, evitando su comercialización, mofa, disminución axiológica o la denigración de las preferencias sexuales respetadas por la mayoría social organizada de nuestros municipio”. ¡Qué modo tan perfecto de establecer la dictadura del disparate! Así, en materia de homofobia, un grupo político decide a fines de milenio resguardar los prejuicios judeocristianos, condimentándolos con su inigualable proceso lógico. El panista Alfonso Azcona Zabadúa predica:

En Veracruz los carnavales (disfrazados) y las semanas santas las toman los homosexuales en avanzadas multitudinarias, muchos de ellos se quedan a residir en este puerto, incluyendo los homosexuales de los alrededores, pero eso sí, todos, absolutamente todos, son de fuera, incluyendo al grupo gay Lenguaje Siglo XXI, quienes enfáticamente declararon: Que debe de existir una comunidad... Probablemente sugieran que cada veracruzano nos hagamos acompañar de un lilo. La tesis, de plano, empobrece y de- 


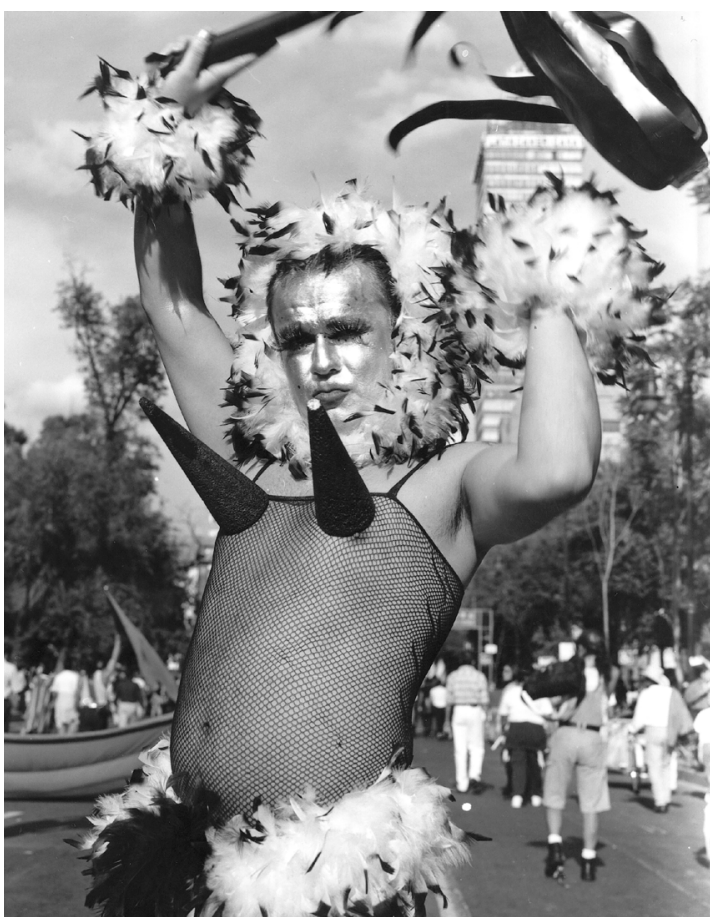

Foto: Arturo Fuentes.

prime ante esta declaración interna que no puede ocultar y se refugian en la declaración de la ONU de que el año 1995 es el Año Internacional de la Tolerancia, sin considerar que significa indulgencia, condescendencia, pero tolerar también significa soportar, sufrir, aguantar, sobrellevar, disimular, y pregunto: ¿por qué imponerlo? (El Financiero, 7 de septiembre de 1995)

La homofobia empieza a situarse en un nivel distinto, cuando, no obstante su ferocidad y los daños que afectivamente causa, es ya imposible alejarla del ámbito del humor involuntario. Así, la esposa del alcalde panista de Guadalajara, César Coll, a la pregunta: “ ¿Tiene conocimiento de que algún homosexual trabaja en su entorno?”, contesta con infalible candor: "Que sepa, no. Nadie me ha dicho: Oiga, soy gay, aquí trabajo” (en Siglo 21, 19 de junio de 1996). Y en Creciendo en el amor, libro de texto obligatorio en escuelas particulares y promovido por las autoridades panistas de Jalisco y Michoacán, se estipula: "La homosexualidad es una costumbre desviada por falta de conciencia. Los homosexuales son neuróticos y sufren porque desvían la complementariedad. La función natural de la sexualidad es agradable debido a su fin procreativo." Mientras la sociedad, ya arraigada en el laicismo, tiende progresivamente a la tolerancia, la derecha insiste, estimulada por el clero, vigoriza su homofobia por ser ésta una de sus grandes señales de identidad. Javier Soto Varela, oficial mayor de Desarrollo Social del Ayuntamiento de Guadalajara, es conminatorio: "En la administración panista que encabeza César Coll Carabias no deben encajar funcionarios que sean homosexuales o que no den un buen ejemplo de su vida personal o familiar... No se vale que en los gobiernos haya homosexuales o personas con una desviación escandalosa" (La Jornada, 18 de marzo de 1996).

La homofobia de los panistas es notable, y llama la atención porque antes del 6 de julio formaba parte de su plan de gobierno. Extinguir a los transgresores es afirmar su parcela en el cielo. Al alcalde panista de León, Luis Quirós Echegaray (El Nacional de León, 26 de abril de 1996), se le pregunta, a propósito de los gays: “ ¿Es natural que exista este tipo de personas?”, y contesta con presteza: "No, no es natural, es natural que exista un burro, sabes que hay un hombre y una mujer, a los de en medio yo no les reconozco, ni creo que la sociedad deba reconocerlos." Y el gobernador de Guanajuato, Vicente Fox es sentencioso (en A.M. de León, abril de 1996):

\section{¿Apoya las acciones del alcalde Quirós contra los grupos} homosexuales?

¿Para qué me mete en este tema? Es una decisión del Ayuntamiento y me parece que la tomaron correctamente, actos degenerados no son buenos para la sociedad, no tiene por qué promoverlos el Estado. Para mí ése es un acto degenerativo.

¿Cuál es su opinión sobre los homosexuales?

Que es un acto degenerativo que va contra la naturaleza humana, es una degeneración. Como ciudadanos merecen todos mis respetos, no los va a apalear nadie, ni los va a molestar nadie, que hagan según su conciencia lo que se les antoje. Pero mi opinión es que es un acto degenerativo, es un acto contra natura.

Vicente Fox asume la Presidencia de la República y la presión de los cambios reales en la sociedad lo obliga a pronunciarse contra la homofobia, sin entender el sentido de la expresión. ¡Éstos son tus dioses, oh Israel! 